Max-Planck-Institut für demografische Forschung

Max Planck Institute for Demographic Research

Konrad-Zuse-Strasse 1 - D-18057 Rostock · GERMANY

Tel +49 (0) 3812081 - 0; Fax +49 (0) 3812081 - 202;

http://www.demogr.mpg.de

MPIDR WORKING PAPER WP 2005-020

AUGUST 2005

\title{
Does the socioeconomic mortality gradient interact with age? \\ Evidence from US survey data and Danish register data
}

Rasmus Hoffmann (hoffmann@demogr.mpg.de)

This working paper has been approved for release by: James W. Vaupel (jwv@ demogr.mpg.de) Head of the Laboratory of Survival and Longevity.

(C) Copyright is held by the authors.

Working papers of the Max Planck Institute for Demographic Research receive only limited review. Views or opinions expressed in working papers are attributable to the authors and do not necessarily reflect those of the Institute. 
Does the socioeconomic mortality gradient interact with age? -

\title{
Evidence from US survey data and Danish register data
}

\author{
Rasmus Hoffmann, M.A. \\ Max Planck Institute for Demographic Research, Rostock \\ University of Rostock, Germany
}

Paper prepared for the XXV IUSSP International Population Conference

in Tours, France, July 2005

June 15, 2005 


\begin{abstract}
The aim of our paper is to provide an answer to the questions if and why social differences in health and mortality decrease with age. Most research confirms this decrease but the reasons for it and the role of unobserved heterogeneity are unknown. The data used for our analysis come from the US Health and Retirement Study ( $n=9376$ ) and from the Danish Demographic Database (Denmark's population above age 58). They offer detailed information about SES and health information. The technique of event-history-analysis is used, and frailty models address mortality selection. A new method is developed to consider systematic difference in the change of average frailty over age between social groups. SES differentials in mortality converge with age in Denmark but not in the US. In both countries, they converge strongly with decreasing health. When controlled for health, the differences are stable across age in both countries. This means that worsening health levels social mortality differences and not increasing age. Controlling for mortality selection removes the converging pattern over age.
\end{abstract}




\section{Introduction}

The impact of the socioeconomic status (SES) on health and mortality has been observed many times in mortality research. Poor groups of people have generally two to three times higher death rates than rich ones (Auerbach and Krimgold 2001:31). The difference in life expectancy for Dutch men between the highest and lowest educational group is 4 years (Stronks 1997:3). In the 1980s, white men in the USA with a family income lower than $\$ 10.000$ had a life expectancy 6.6 years lower than those with an income higher than $\$ 25.000$ (Smith 1999:147). Within-country differences are at times much higher than international differences, e.g. the male mortality rate of those aged under 65 is higher in Harlem, New York, than it is in Bangladesh (McCord and Freeman 1990).

In spite of overall decreasing mortality levels, economic growth, and improvements in medicine, mortality differentials between income groups and educational groups increased at ages 25 to 64 between 1960 and 1986 in the USA (Pappas et al. 1993:103). In the 1980s, this was also the case for all countries for which data are available (Valkonen 2001:8826).

Increasing differences here means increasing relative differences. Absolute differences, by contrast, may have decreased because of the overall declining level of mortality. However, results for the USA indicate that lower class mortality did not decline at all, which means that even absolute differences have increased (Auerbach and Krimgold 2001).

There is an ongoing debate about the causality of these mortality differentials. Some authors assume that health inequalities arise prior to differences in SES and that especially in later working ages the health status translates into SES via the ability to work (Smith 1999). Smith (2003 and 2004) finds that in pre-retirement ages new health events have a strong negative impact on income and wealth. In the following, we will leave this question aside and assume, based on the majority of research findings, that the main direction of causality especially in old ages goes from SES to health and that the notion of "SES impact on health and mortality" is thus generally justified (Fox et al. 1985, Goldman 2001). The concrete pathway of this impact will be further illustrated below. 
While socioeconomic differences in health and mortality are well established by research findings, it is unclear whether these differences are stable across the life course or whether they decrease in old age. The latter is the most common finding made by researchers and has been explained using the following arguments:

1. Aging works as a leveler of social differences because biological processes assume dominance over social determinants and eventually everybody must die, regardless of social class (Liang et al. 2002:295).

2. The welfare state reduces socioeconomic differences in old age through benefits and social policy.

3. The impact of past experiences that are responsible for health differences, e.g. working conditions, fades out at old age.

4. The observed mortality differences get smaller in old age but only on the aggregate level because the surviving population is more homogeneous due to selective mortality and unobserved heterogeneity.

The last argument means that the impact of SES on mortality on the individual level can be stable or even increases with age. This opposite result is based on the following assumptions:

5. The impact of past unhealthy experiences, e.g. unhealthy working conditions and smoking, is postponed to older ages.

6. Past experiences, e.g. education, accumulate and may interact with other factors, e.g. economic and social capital. The health outcome of this accumulation is incorporated into the "health stock".

7. Vulnerability increases in old age and makes differential exposures more harmful (House et al. 1994:221).

For a discussion of arguments 2 to 6, see Ross and $\mathrm{Wu}(1996: 107)$. For a more detailed elaboration of the cumulative advantage/disadvantage theory, see Crystal and Shea (1990), O'Rand (1996) and Dannefer (2003). As stated above, most research finds decreasing socioeconomic mortality differences with rising age (see e.g. Liang et al. 
2002 and Marmot/Shipley 1996). But only few researchers have addressed this question in detail, some having attempted to identify a possible bias because of mortality selection and other problems of the measurement of mortality differences across different ages. House et al. (1994) find generally converging mortality differences but, depending on the indicator for SES, also an inconsistent pattern in the age trajectory of mortality differences. They stress the possibility that mortality selection causes convergence. After applying a method to account for a sample selection bias, Beckett (2000) concludes that the observed convergence is not biased by mortality selection. Ferraro and Farmer (1996), by contrast, show that mortality selection biases the measurement of gender and racial health differences. Ross and $\mathrm{Wu}$ (1996) reveal diverging health differences with increasing age; Fox et al. (1985) show similar social mortality differences below and above age 75. Otterblad Olausson (1991) finds divergence for women and convergence for men in Sweden, which is similar to the recent results by Huisman et al. (2004), who show in an international comparison that relative mortality differences by education and housing tenure did not decline with age for women in some countries.

The aim of this paper is to gain deeper insight into the age pattern of socioeconomic mortality differences, to find possible reasons for such an interaction with age and also for the inconsistent previous research results on this topic.

The theoretical background of this research is the question whether the interplay between social and biological factors in determining health and mortality of an individual is changing over the life course or not. Another related question is how we can understand social inequality in old age. Health may become so important for the living conditions and quality of life that it becomes an important aspect of social inequality. Our study aims at finding out whether the impact of SES decreases with age or not and to what extent the connection between SES and mortality is mediated by the health status.

To motivate the choice of variables and models in the empirical part of this paper, we will give an overview of possible causal pathways from SES to mortality. According to the majority of studies, material factors are responsible for a large part of socioeconomic mortality differences (e.g. Schrijvers et al. 1999). Money can buy healthy food, good housing, better medical treatment, and other goods that are directly or indirectly relevant 
to maintaining a good health status. Education is important to get knowledge about health risks and healthy behavior and in providing cognitive skills for dealing with complex information such as the association of behavior on one's personal health and the structures of the health care system. Social capital is helpful when a person needs information, connections, and emotional and practical help.

Stress and behavior are factors that are on an intermediate level between SES and mortality. Stress is likely to be higher and health behavior is poorer in lower status groups. Finally, on the societal level the health care system is an important factor that has an influence on whether a low status can cause poor health and higher mortality or not (Kunst 1997).

\section{Data and Variables}

\subsection{USA}

The US data come from the Health and Retirement Study (HRS) and the study of Assets and Health Dynamics among the oldest old (AHEAD). These are two representative studies conducted by the Institute of Social Research (ISR), University of Michigan, that were started separately in 1992 and 1993 respectively and then combined in 1998 with a follow-up every second year (Soldo et al. 1997). Since HRS focuses on retirement ages and AHEAD on ages of $70+$, we merged them with the help of some data sets prepared by RAND (for information see http://hrsonline.isr.umich.edu).

This resulted in a sample of 9376 persons born before 1934 (aged 59 to 107) surveyed from 1992 to 2000, with 2608 deaths during observation. We excluded black persons from the analysis. Institutionalized persons were already excluded in the original baseline sample but surveyed in the institution during the follow up interviews. This may cause a bias. For example, single persons, persons with poor health, and women are more likely to be in a nursery home and thus they are more likely to be underrepresented in the sample (Grundy and Sloggett 2003:936). Huisman et al. (2003) tested this bias and found that samples that exclude institutionalized persons underestimate socioeconomic health differences in older ages. But the HRS sample only excludes them 
at baseline but follows them in the institutions. Thus, from wave to wave the percentage of people living in a nursery home comes closer to the percentage in the US population until for the HRS wave of the year 2000 the differences are negligible. It is unlikely that our results are biased substantially by this slight under-representation.

The variables allow a detailed and time varying measurement of SES, health status, and some control variables. Except for education, parents' mean age at death, and having children, all variables in the following list are time varying ones.

Education is measured in years of education (levels: 0-7, 8-15, 16+).

Wealth includes all assets of the household in which the person lives (bank account, real estate, shareholdings etc.) and is measured on three levels: lowest quartile, second lowest quartile, and above median wealth.

Income is the net annual household income divided by a weighted number of persons living in the household (net equivalent income). The weight is 1 for the first person and 0.7 for all other persons in the household. Like wealth, income is measured on three levels: lowest quartile, second lowest quartile, and above median income.

Parents' mean age at death is the mean age at death of both parents (levels: $-75,76+$ ). Under certain conditions, it captures the genetic constitution that is transferred from the parents to their children; see section 4.1.

Children is an indicator for any own children (levels: yes, no). This variable measures one aspect of social capital, namely if it is possible that a child looks after the old person, but it can not be treated as a social status variable. This is because it measures many different things. For example, having numerous children is an indicator of low social status and may be the cause for higher mortality whereas having no children may be the consequence of bad health (Doblhammer 2000).

Labor force status. This variable differentiates between working, being retired/disabled and not being in the labor force. While the labor force status is to a large extent a function of age and health (which we control for by using other variables), it additionally captures information on social status and every-day life - information that is predicting mortality. 
Marital status is not a social status measure in a strict sense, but it is related to SES. Firstly, marital status depends partly on social status, e.g. persons with a low social status are more likely to live alone. Secondly, marital status has a high impact on the social status in the sense that divorce or widowhood is often followed by a loss of economic and/or social capital. Moreover, marital status has an influence on health and mortality independent of SES. In this analysis, we combine divorced with never married persons because they both are very small groups that show a similar level of mortality.

Health behavior is an additive index focusing on three items that have shown to be important correlates of health: 1. physical activity (the persons were asked if they engage in strong physical activity once a week or more), 2. ex-smoker, 3. current smoker (the respondants were asked if they consider themselves being an exsmoker or smoker). From the resulting four different categories of this score (-1 to 2), the last two (with the worst health behavior) have been collapsed into one category because both of them were small.

Self-rated health. The question on self-rated health is asked in the traditional way, with five categories of answers provided. To limit the overall number of categories we merged the first two categories "excellent" and "very good", because their meanings differ only slightly.

Objective health is another index that includes 1 . being in a hospital for more than 10 days per year, 2. limitations in activities of daily living (ADL), 3. body mass index (BMI) at baseline $<21.4$ for men and $<19.5$ for women (=lowest decile), and 4 . loss of weight of more than 10 per cent between two waves (= two years).

Some variables have been tested in previous models and then skipped because they did not show significant results after controlling for other variables. The omitted variables are: occupational group, parents' education, church attendance, children living nearby, drinking alcohol, high BMI, and a 10 per cent gain in body weight. 


\subsection{Denmark}

The Danish data are register data from the Danish Demographic Database, which has been created in 2000. It is maintained by Statistics Denmark, the central statistical office of Denmark (www.dst.dk), and the Danish Center for Demographic Research. It combines data from different registers that exist from 1980 onwards. Registers cover the entire Danish population, providing annual information. The information from these different sources can be linked by an individual person identification number. Our dataset includes 1.090 .897 women and 938.427 men, thus a total of 2.029 .324 persons aged 59 years or older. They are observed from 1980 to 2002. This means that the birth cohorts 1874 to 1933 are followed over 23 years, and the cohorts from 1934 to 1941 for a shorter period (starting from the lower horizontal line of a Lexis-diagram).

The variables are similar to the variables in the HRS dataset. The use of a category for "not known" for most of the variables follows the principle that it is better to have such a category in a model than to drop all persons where only some information is missing. Generally, the register data have a very low percentage of missing data. Where missing data could be imputed without strong assumptions, e.g. when income is missing only for some years, this has been done. The measurement and treatment of missing values and other exceptions is as follows (for all levels of all variables, see Table 2):

Education is measured in years of schooling (levels: $-7,-8,-9,-10$, and $11+$ ). The variable for education is problematic because it is only available for persons born after 1920. As a consequence, there is no information about education for persons above age 82. The information was collected for all persons in the last Danish census in 1970 and later considered to be unreliable for persons above age 50 at the time of the census. These persons are coded as education not known, thus mainly old persons are included in this category. Tests with models without education and models restricted to persons younger than age 83 show that the information systematically missing for education does neither change the results for the other variables nor for the other analytical steps in our study. This is mainly because education has no high importance as a social predictor for 
mortality. Thus, it would not be justified to exclude older persons from the analysis.

Wealth includes all assets of the household in which the person lives (bank account, real estate etc.) and is measured on four levels representing the four wealth quartiles. Shareholdings are included in the measurement of wealth since 1995.

Income is the individual gross annual income. It is measured in six categories based on percentiles that are made for every year from 1980 to 2002.

Children is an indicator that, unlike in the HRS data, means not only that the persons have children of their own but also that they are currently living in the household (levels: yes, no).

Source of main income in the Danish data is comparable to Labor force status in the US data. This variable shows whether the persons surveyed receive the main part of their income from a normal pension, an early retirement pension, normal wages or salaries, income from a business of their own, or from transfer income (e.g. unemployment or sickness benefits).

Marital status is measured in the traditional four categories: married, divorced, widowed, and never married.

Days in hospital is the only health measure that we obtained from the Danish register system. Even if, compared to the detailed information about different aspects of health in the US data, this variable can only be an approximation, it shows surprisingly similar results. Thus, the analysis that uses health as a variable will be repeated for Denmark; this in order to compare the results with the US results, but in other cases the health analysis will be limited to the US. The variable measures the days spent in hospital in one year on six levels.

Occupation was excluded in the analysis of the US data mainly because of the need to limit the number of variables and categories due to insufficient sample size. For the Danish data, there is no such need; thus the impact of occupation on mortality is shown in some models. But to keep the analysis for the two countries comparable it is excluded in other models. Occupation is measured in the classical categories based on the distinction between skilled and unskilled on the one side, and manual and non-manual on the other (see Table 2). 
Type of dwelling provides a distinction between different types of housing that may have an impact on health and mortality beyond the overall living standard. It also provides some information about the degree of urbanization. A single house with garden is the typical suburban type of dwelling that most elderly people in Denmark live in. An apartment is typical for larger cities whereas country house stands for a rural area. Inhabitants of nursery homes which have high mortality are placed in the category shared dwelling. But since not exclusively this group of persons is in this category, a further interpretation of this group is not possible.

Square meters is the size of the dwelling per person, i.e. divided by the number of persons living in the dwelling.

For both countries, age is controlled for by using four age groups (59-69, 70-79, 80-89, 90+) for a piecewise constant baseline or, as in other models, by using a Gompertzshaped baseline risk. Sex is controlled for by running separate models for each sex. We also checked and found that period or cohort effects do not bias the presented results. In many parts of this paper, we only show results for men; this in order to reduce the amount of figures and aspects to consider in this paper.

\section{Methods}

\subsection{General Method}

We apply an event-history-analysis with a model for the force of mortality. This includes a baseline for the basic time variable age that is Gompertzian or it is piecewise constant in all models that include an interaction with age. The results shown are computed with STATA 8. The baseline for age covers the age range from 59 to 107 (to 111 in Denmark) whereas the observation period is only 8 years, namely from 1992 to 2000 (23 years in Denmark, from 1980 to 2002). Thus, the cohorts are not real cohorts but partly synthetic ones in the sense that in spite of the longitudinal data, not all individuals are really observed from age 59 to death. 
The analysis of selective mortality is limited by the fact that only persons who survived until age 59 are included in the study. Persons who entered the study after age 59 are left-truncated, i.e. we only consider the period at risk after the respondents have entered the sample. STATA allows taking into account left-truncated cases by distinguishing between "time under risk" and "time under observation". Here "time under risk" starts at age 59 for all persons and "time under observation" starts at the individual age of entry. STATA computes the individual probability that a person survives from age 59 to the age of entry based on the known characteristics of this persons and other persons who are observed from age 59 onwards.

Different models are used in different steps to draw conclusions about the causal relationships between the predictor variables and their impact on mortality. Basically, relative mortality rates are computed using different interactions and a term for unobserved heterogeneity. The general formula for the model is:

$\ln \mu_{i}(x)=y(x)+\sum_{j} \alpha_{j} X_{i j}+\sum_{k} \beta_{k} W_{i k}(x)+\sum_{\{l, m:(l, m) \neq(1,1)\}} \chi_{l m} I\{A=l, B(x)=m\}+U_{i}$ $(1)$,

where $\mathrm{y}(\mathrm{x})$ is the baseline hazard that depends on age, $\mathrm{X}$ is a matrix of time constant variables and $\mathrm{W}$ denotes a matrix of time-varying variables that depend on age. The fourth term represents an interaction between a time constant and time varying variable, $\mathrm{A}$ and $\mathrm{B}$, where $I$ is an indicator that equals 1 for one specific combination of the levels of the two variables and that equals 0 otherwise. $U$ stands for a heterogeneity term that is assumed to measure an individually constant frailty that is gamma distributed in the sample.

\subsection{Method to Control for Unobserved Heterogeneity}

Statistical packages like STATA account for left truncation in the way described in the former section and it is possible to include the term $U$ for unobserved heterogeneity in the model. But to fully explore the selection hypothesis, we need to account somehow 
for a longitudinal perspective, i.e. we need to make assumptions on past mortality experienced differently by the social subgroups of the cohorts included in the observation period. This is necessary to correct for systematic difference in the decrease of average frailty over age between social groups or generally between groups with different mortality. According to the basic idea of an individually constant frailty, average frailty in a population decreases with age because individuals with high frailty die earlier. This decrease is faster in low SES groups because mortality is higher. The resulting difference in the average frailty between SES groups in high age biases the usual measurement of mortality differences. This can be seen in many studies revealing a mortality cross over in high ages between smokers and non-smokers or black and white persons (Nam 1995). The crossover probably does occur not because smoking becomes healthy in high age but because very old smokers are selected and have low frailty.

We try to correct for these different frailty changes in a way that is superior to what e.g. STATA or aML can do: Based on the proportional-hazards model, Vaupel et al. (1979) showed that

$\bar{\mu}(x)=\bar{z}(x) \mu(x)$

where

$\bar{z}(x)=\bar{s}(x)^{\sigma^{2}}$

where $\bar{z}(x)$ is the average frailty of those alive at age $\mathrm{x}, \bar{s}$ is the observed survivorship function and $\sigma^{2}$ is the degree of heterogeneity, namely the variance of the frailty distribution which we assume to be gamma distributed with a mean of 1 .

We apply the following method only to the Danish data because here we have more cases and a longer observation period than for the USA. We simplify the data by dividing the population into poor and rich people, i.e. the lowest income quartile and the rest. For each group we calculate the survivorship and the mortality hazard in the lexistrapezoid a) in Figure 1 directly from the data. First, we tried to estimate the average frailty for these two social groups in this trapezoid with a model like equation (1) without interactions. Unfortunately, these estimations were not successful. Either the 
models did not converge or the results for $\sigma^{2}$ had such large confidence intervals that even with several hundred of thousands of cases the measurement of heterogeneity was unreliable. Our estimated values from many different attempts range from 0.01 to 0.2. This is in the order of magnitude where other people have found heterogeneity. We found corresponding results from different studies with different approaches, ranging from 0.1 to 0.5 (Manton, Stallard and Vaupel 1986; Horiuchi and Wilmoth 1998; Caselli, Vaupel and Yashin 2000; Barbi 2003). We think that theoretical and empirical evidence for the existence of such heterogeneity is strong enough to assume a value for $\sigma^{2}$ and impose it on the data. This allows us to compute $\bar{z}(x)$ in equation (3) and then $\mu(x)$ in equation (2) above, which represents a hazard net of the impact of frailty. We do the same for the next ten years of age but multiply the frailty from the second age group by the frailty from the first step:

$\bar{\mu}(x+10)=\bar{z}(x) \bar{z}(x+10) \mu(x+10)$

We repeat this calculation for the third and the fourth age group and each time we multiply all the values for the frailty from the younger age groups. The assumption is that the divergence of frailties occurring from ages 60 to 70 because of different selective forces in different SES groups is the same as the process happening to the persons in lexis trapezoid b) in Figure 1 before we started to observe them. Following the Gamma-Model, we use the same values for the heterogeneity as to different age groups even if this may be a simplistic assumption given our theoretical understanding that heterogeneity decreases with age by selective mortality. The logic of our approach is analogous to a synthetic cohort and allows us to reconstruct the differential change of frailties in different social groups over the whole age range of the sample. Our approach is able to reveal corrected and thus higher social mortality differences at high ages. 
Figure 1: Lexis Diagram

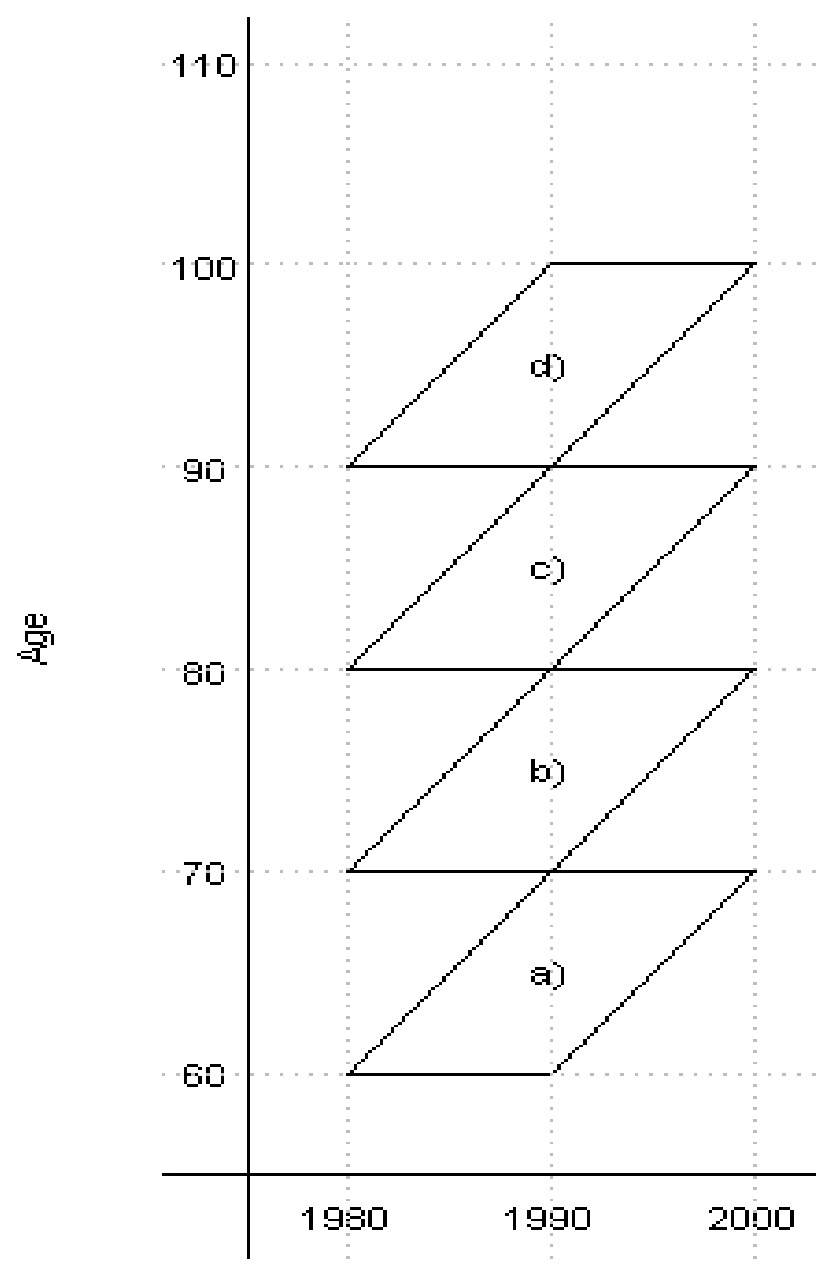

Year 


\section{Results}

\subsection{Main Effect Models}

Table 1 shows the relative risks of dying for the USA. The underlying models are without interactions and separate for men and women. The gompertz-shaped baseline for the absolute risk is not shown. The baseline risk roughly doubles with every ten years of age.

Model 1 contains the univariate results of each variable separately. All variables show the expected association with mortality and all of them are significant, except marital status for women and having children for men. Surprisingly, men with 8 to 15 years of education do not have a significantly lower mortality compared to those with 0 to 7 years of education. 
Table 1: Event history model for mortality, USA

\begin{tabular}{|c|c|c|c|c|c|c|c|}
\hline & \multicolumn{2}{|c|}{ MODEL 1} & \multicolumn{2}{|c|}{ MODEL 2} & \multicolumn{2}{|c|}{ MODEL 3} \\
\hline & & male & female & male & female & male & female \\
\hline \multirow{2}{*}{$\begin{array}{l}\text { parents' age at } \\
\text { death }\end{array}$} & -75 & 1 & 1 & & & 1 & 1 \\
\hline & $76+$ & $0.86^{* * *}$ & $0.77^{* * *}$ & & & 0.92 & $0.87^{* *}$ \\
\hline \multirow[t]{3}{*}{ education } & $0-7$ & 1 & 1 & 1 & 1 & 1 & 1 \\
\hline & $8-15$ & 0.94 & $0.78^{* * *}$ & $1.20 * *$ & 0.92 & $1.37^{* * *}$ & 1.03 \\
\hline & $16+$ & $0.59 * * *$ & $0.63\left(^{* * *}\right)$ & 0.99 & 0.86 & $1.31\left(^{* *}\right)$ & 0.94 \\
\hline \multirow[t]{2}{*}{ children } & no & 1 & 1 & 1 & 1 & 1 & 1 \\
\hline & yes & 0.93 & $0.83^{* *}$ & 0.98 & 0.85 ** & 0.99 & 0.87 * \\
\hline \multirow[t]{3}{*}{ labor force status } & work & 1 & 1 & 1 & 1 & 1 & 1 \\
\hline & retired/disabled & $2.48 * * *$ & $3.36 * * *$ & 2.24 *** & $3.02 * * *$ & $1.54 * * *$ & $2.17^{* * *}$ \\
\hline & not in labforce & $3.17^{* * *}$ & $1.83^{* * *}$ & $2.54^{* * *}$ & $1.63^{* *}$ & $1.97^{* *}$ & 1.20 \\
\hline \multirow[t]{3}{*}{ marital status } & married & 1 & 1 & 1 & 1 & 1 & 1 \\
\hline & widowed & 1.05 & 1.10 & 0.95 & 0.90 & 1.01 & 0.91 \\
\hline & divorced/never & $1.46^{* * *}$ & 1.17 & $1.25 * *$ & $0.80 *$ & 1.22 * & $0.77^{* *}$ \\
\hline \multirow[t]{3}{*}{ wealth (percentiles) } & $0-25$ & 1 & 1 & 1 & 1 & 1 & 1 \\
\hline & $25-50$ & 0.88 * & $0.71^{\star \star \star}$ & 0.92 & $0.78 * * *$ & 1.05 & 0.91 \\
\hline & $50-100$ & $0.54^{* * *}$ & $0.57\left(^{* * *}\right)$ & $0.65^{* * *}$ & $0.72\left(^{(* *}\right)$ & $0.87\left(^{*}\right)$ & 0.90 \\
\hline \multirow[t]{3}{*}{ income (percentiles) } & $0-25$ & 1 & 1 & 1 & 1 & 1 & 1 \\
\hline & $25-50$ & $0.75^{* * *}$ & $0.60^{* \star *}$ & 0.86 ** & $0.67^{* * *}$ & 0.95 & $0.75^{* * *}$ \\
\hline & $50-100$ & $0.522^{\star \star *}$ & $\left.0.544^{(* *}\right)$ & $0.72\left(^{\star \star *}\right)$ & $0.655^{(* * *)}$ & $0.82\left({ }^{\star *}\right)$ & $0.74\left(^{* * *}\right)$ \\
\hline \multirow{3}{*}{$\begin{array}{l}\text { health behavior } \\
\text { (active, ex-smoker, } \\
\text { smoker) }\end{array}$} & good & 1 & 1 & & & 1 & 1 \\
\hline & fair & $2.21^{* * *}$ & $3.34 * * *$ & & & $1.73^{* * *}$ & $2.40 * * *$ \\
\hline & poor & $4.38^{* * *}$ & $4.62\left(^{* * *}\right)$ & & & $2.78\left(^{* \star *}\right)$ & $2.95\left(^{\star \star *}\right)$ \\
\hline \multirow[t]{4}{*}{ self rated health } & excel/very good & 1 & 1 & & & 1 & 1 \\
\hline & good & $1.58^{* * *}$ & $1.65^{* * *}$ & & & $1.32 * * *$ & $1.44^{* * *}$ \\
\hline & fair & $2.60 * * *$ & $2.68 * * *$ & & & $1.85\left(^{* * *}\right)$ & $1.92\left(^{\star * *}\right)$ \\
\hline & poor & $6.11^{* * *}$ & $4.52^{* \star *}$ & & & $3.38^{* \star *}$ & $2.6\left(^{* * *}\right)$ \\
\hline \multirow{4}{*}{$\begin{array}{l}\text { objective health } \\
\text { (Hospital, adl, } \\
\text { thin, weight loss) }\end{array}$} & excel/very good & 1 & 1 & & & 1 & 1 \\
\hline & good & $2.08^{* * *}$ & $1.76^{* * *}$ & & & $1.36^{* \star *}$ & $1.22 * * *$ \\
\hline & fair & $3.56\left(^{* * *}\right)$ & $3.43^{* * *}$ & & & $1.74\left(^{* * *}\right)$ & $1.98^{* * *}$ \\
\hline & poor & $5.03\left({ }^{* * *}\right)$ & $4.77\left(^{* * *}\right)$ & & & $2.27(* \star *)$ & $2.39{ }^{* * *}$ \\
\hline
\end{tabular}

Stars in brackets mean that the parameter value is significantly different from 1 but not from the previous variable level.

In Model 2, all variables that directly or indirectly describe SES are included simultaneously whereas health variables are excluded. Naturally, the mortality differences between the levels of most of the variables get smaller than in Model 1 but, for example, income and wealth still have an independent significant impact on mortality. We see that when wealth and income are controlled for, higher education no longer has a positive separate impact. Men with an intermediate level of education even have significantly higher mortality than lowly educated men (see discussion below). Having children reduces mortality for women but not for men. Further, the retired, the 
disabled, and persons who are not in the labor force have a higher mortality than those who are working.

Widows do not display a mortality that is significantly different from married persons. Men who are divorced or who have never married have a higher mortality whereas women in the same group have a lower one. Interestingly, the relative mortality risk of divorced or never married women turned from an insignificantly higher mortality according to the univariate results of Model 1 to a significantly lower mortality risk in Model 2. Finally, income and wealth both have a strong diminishing impact on mortality.

One intermediate step between Models 2 and 3 is not shown here: it adds only health behavior to the SES variables and shows that the measured items of health behavior (physical activity, being an ex-smoker, and being a smoker) changes the coefficients only slightly and do not remove the significance of any socioeconomic variables. This means that socioeconomic mortality differences to a large extent can not be explained by physical activity or smoking.

Model 3 is the full model, where the three health variables and also parents' mean age at death are added. Controlling for health means that we see the remaining impact of SES on the transition from a given health status to death. This perspective will be developed further in section 4.2. where we look at the interaction between SES and health. Technically, controlling for health means that we control for an intermediate step in the causality chain from SES via health to mortality. This is problematic because of the risk of "controlling away" socioeconomic differences, since health is already correlated with SES (Martelin 1996:127; Hoover 2003:123). But as one model among others it helps to gain insight in the interplay between SES, health and mortality.

We see that a high parents' mean age at death significantly reduces the mortality of women, and this supports the assumption that common genes in a family contribute to longevity. This interpretation is likely to be true, not least because the inclusion of parents' education in the model as an indicator of their social status does not change the impact of their age at death (results not shown). Thus, in Model 3 parents' SES is not a common background factor influencing both the parents' mean age at death and the mortality of the respondent. The genetic explanation is less likely if one assumes that parental education is not a good indicator for childhood conditions. 
Table 2: Event history model for mortality, Denmark

\begin{tabular}{|c|c|c|c|c|c|c|c|}
\hline & & \multicolumn{2}{|c|}{ MODEL 4} & \multicolumn{2}{|c|}{ MODEL 5} & \multicolumn{2}{|c|}{ MODEL 6} \\
\hline & & male & female & male & female & male & female \\
\hline education & $\begin{array}{l}-7 \\
-8 \\
-9 \\
-10 \\
11+ \\
\text { not known }\end{array}$ & $\begin{array}{r}1 \\
0.99 \\
0.98 \\
0.80 \\
0.73 \\
1.11\end{array}$ & $\begin{array}{r}1 \\
0.99 \\
0.91 \\
0.79 \\
0.78 \\
0.95\end{array}$ & $\begin{array}{r}1 \\
1.04 \\
1.08 \\
0.98 \\
0.92 \\
1.19\end{array}$ & $\begin{array}{r}1 \\
1.01 \\
0.96 \\
0.88 \\
0.87 \\
1.04\end{array}$ & $\begin{array}{r}1 \\
1.01 \\
1.04 \\
0.98 \\
0.95 \\
1.09\end{array}$ & $\begin{array}{r}1 \\
0.98 \\
0.96 \\
0.91 \\
0.93 \\
0.97\end{array}$ \\
\hline children & $\begin{array}{l}\text { No } \\
\text { Yes }\end{array}$ & $\begin{array}{r}1 \\
0.70\end{array}$ & $\begin{array}{r}1 \\
0.87\end{array}$ & $\begin{array}{r}1 \\
0.72\end{array}$ & $\begin{array}{r}1 \\
0.73\end{array}$ & $\begin{array}{r}1 \\
0.76\end{array}$ & $\begin{array}{r}1 \\
0.76\end{array}$ \\
\hline main income & $\begin{array}{l}\text { Pension } \\
\text { early pension } \\
\text { Wages } \\
\text { business income } \\
\text { transfer income } \\
\text { not known }\end{array}$ & $\begin{array}{r}1 \\
1.02 \\
0.82 \\
0.74 \\
1.55 \\
1.88 \\
\end{array}$ & $\begin{array}{r}1 \\
0.99 \\
0.82 \\
0.84 \\
1.51 \\
2.44\end{array}$ & $\begin{array}{r}1 \\
0.93 \\
0.84 \\
0.82 \\
1.20 \\
1.06\end{array}$ & $\begin{array}{r}1 \\
0.89 \\
0.77 \\
0.90 \\
1.18 \\
1.01\end{array}$ & $\begin{array}{r}1 \\
1.11 \\
1.08 \\
0.98 \\
1.22 \\
1.17\end{array}$ & $\begin{array}{r}1 \\
1.12 \\
1.01 \\
1.04 \\
1.31 \\
1.14\end{array}$ \\
\hline marital status & $\begin{array}{l}\text { Married } \\
\text { Divorced } \\
\text { Widowed } \\
\text { never married }\end{array}$ & $\begin{array}{r}1 \\
1.51 \\
1.23 \\
1.34\end{array}$ & $\begin{array}{r}1 \\
1.38 \\
1.18 \\
1.23\end{array}$ & $\begin{array}{r}1 \\
1.50 \\
1.33 \\
1.23\end{array}$ & $\begin{array}{r}1 \\
2.46 \\
2.22 \\
2.16\end{array}$ & $\begin{array}{r}1 \\
1.26 \\
1.19 \\
1.23\end{array}$ & $\begin{array}{r}1 \\
1.94 \\
1.88 \\
1.89\end{array}$ \\
\hline occupation & $\begin{array}{l}\text { unskilled manual } \\
\text { Helper } \\
\text { skilled manual } \\
\text { non manual } \\
\text { self employed } \\
\text { not known }\end{array}$ & $\begin{array}{r}1 \\
0.97 \\
0.95 \\
0.79 \\
0.80 \\
1.08\end{array}$ & $\begin{array}{r}1 \\
0.75 \\
0.91 \\
0.82 \\
0.87 \\
0.97\end{array}$ & & & & \\
\hline wealth (percentiles) & $\begin{array}{l}0-25 \\
25-50 \\
50-75 \\
75-100 \\
\text { not known }\end{array}$ & $\begin{array}{r}1 \\
1.08 \\
0.96 \\
0.77 \\
1.29\end{array}$ & $\begin{array}{r}1 \\
0.98 \\
0.89 \\
0.76 \\
2.73\end{array}$ & $\begin{array}{r}1 \\
1.03 \\
1.09 \\
1.04 \\
1.19\end{array}$ & $\begin{array}{r}1 \\
0.97 \\
1.05 \\
1.09 \\
2.25\end{array}$ & $\begin{array}{r}1 \\
0.96 \\
1.06 \\
1.08 \\
1.17\end{array}$ & $\begin{array}{r}1 \\
0.95 \\
1.06 \\
1.15 \\
1.99\end{array}$ \\
\hline income (percentiles) & $\begin{array}{l}0-10 \\
10-25 \\
25-50 \\
50-75 \\
75-90\end{array}$ & $\begin{array}{r}1 \\
0.59 \\
0.33 \\
0.36 \\
0.32\end{array}$ & $\begin{array}{r}1 \\
0.64 \\
0.32 \\
0.39 \\
0.36\end{array}$ & $\begin{array}{r}1 \\
0.64 \\
0.32 \\
0.36 \\
0.33\end{array}$ & $\begin{array}{r}1 \\
0.69 \\
0.26 \\
0.31 \\
0.28\end{array}$ & $\begin{array}{r}1 \\
0.62 \\
0.36 \\
0.41 \\
0.38\end{array}$ & $\begin{array}{r}1 \\
0.63 \\
0.28 \\
0.32 \\
0.28\end{array}$ \\
\hline & $\begin{array}{l}90-100 \\
\text { not known }\end{array}$ & $\begin{array}{r}0.25 \\
11.26\end{array}$ & $\begin{array}{r}0.32 \\
13.69\end{array}$ & $\begin{array}{l}0.28 \\
9.15\end{array}$ & $\begin{array}{l}0.23 \\
5.60\end{array}$ & $\begin{array}{l}0.32 \\
3.02\end{array}$ & $\begin{array}{l}0.24 \\
2.40\end{array}$ \\
\hline days in hospital & $\begin{array}{l}0-3 \\
4-7 \\
8-14 \\
15-30 \\
31-61 \\
62-\end{array}$ & $\begin{array}{r}1 \\
3.00 \\
3.71 \\
6.47 \\
13.24 \\
28.68\end{array}$ & $\begin{array}{r}1 \\
2.76 \\
3.22 \\
5.11 \\
9.75 \\
22.11\end{array}$ & & & $\begin{array}{r}1 \\
2.97 \\
3.63 \\
6.21 \\
12.05 \\
23.50\end{array}$ & $\begin{array}{r}1 \\
2.81 \\
3.28 \\
5.16 \\
9.35 \\
17.63\end{array}$ \\
\hline dwelling & $\begin{array}{l}\text { single house } \\
\text { Apartment } \\
\text { terraced house } \\
\text { country house } \\
\text { shared dwelling } \\
\text { other/not known }\end{array}$ & $\begin{array}{r}1 \\
1.34 \\
1.26 \\
0.88 \\
2.47 \\
7.23 \\
\end{array}$ & $\begin{array}{r}1 \\
1.21 \\
1.24 \\
0.97 \\
2.76 \\
8.57\end{array}$ & & & & \\
\hline square meters & $\begin{array}{l}0-29 \\
30-59 \\
60-79 \\
80+ \\
\text { not known } \\
\end{array}$ & $\begin{array}{r}1 \\
0.79 \\
0.72 \\
0.65 \\
4.22 \\
\end{array}$ & $\begin{array}{r}1 \\
0.68 \\
0.61 \\
0.53 \\
7.54 \\
\end{array}$ & & & & \\
\hline
\end{tabular}

Table 2 presents the relative risks of dying for Denmark in the same way as Table 1 did for the USA. We do not display the level of statistical significance here because with 
about one million cases for each sex virtually all differences are significant even if there are many more variables and variable levels than for the US. As in Table 1 the model on the left (Model 4) shows the univariate results for each variable separately. As to education, we do not see many differences in mortality between the lower educated groups. Those with 11 or more years of schooling have a mortality that is about 25 percent lower than for those with up to 7 years. Having children in the household seems to be more beneficial to men than to women, maybe because elderly men receive help from their children more so than elderly women. The variable source of income reveals, as expected, that those who still work have a lower mortality, but this difference disappears when health is controlled for, as in Model 6. Getting transfer income is combined with higher mortality but this disadvantage also gets smaller when health is controlled for. Marital status shows the normal pattern: married persons have the lowest mortality, followed by widowed persons for whom living without a partner seems to be less dangerous than for never married persons and especially for the divorced, which have the highest mortality because their single status is associated with a greater number of personal problems and an abrupt decline of the social network. As to occupation, we see declining mortality for the higher occupational status. The group of male helpers is with 0.06 percent of all men negligibly small and does not have as significant a mortality advantage as female helpers compared to the reference category of unskilled manual workers.

The wealth quartiles show a lower mortality only for the wealthiest quartile, in contrast to the US results where already the second quartile has a lower mortality than the poorest. The opposite is true for income: here, one has to look at the lower end of income distribution to find significant mortality differences, from the $25^{\text {th }}$ percentile upwards there are no longer any large mortality differences. This is also different to the US where, at least for men, mortality differences are still large between the second quartile and the persons above the median. The interpretation is that because in Denmark the income level is high and more equally distributed than in the USA, there is a smaller fraction of persons, about 25 percent, that has financial problems serious enough to affect health and mortality, especially because medical services in Denmark rely less on individual income than on services provided by the state. The variable for 
days spent in hospital shows a very steep mortality gradient where even within the period of one week there are extreme mortality differences.

Compared to the reference category for dwelling, that is "single house with garden", those living in an apartment or a terraced house have a higher mortality. The countryside is combined with lower mortality. Shared dwelling is combined with very high mortality. As mentioned above, this is probably due to the fact that many nursery home residents are in this category. Interestingly, the differences between different kinds of dwellings do not change when control variables are added to the model (results not shown), thus the differences seem to be caused by the kind of dwelling, really, and not just by related differences in social status or health. The opposite is true for the clear mortality gradient that exists between different sizes of dwellings: this gradient disappears if controlled for social variables. Thus in a univariate model square meters are only an indicator for the social status and do not affect health and mortality on their own.

Model 5 includes a number of variables for SES that was also used to analyze the HRS data. Some major effects of these control variables on the hazard ratios will be described briefly now: The mortality difference of about 25 percent between the highest and lowest educated persons in Model 4 reduces to about 10 percent when income and wealth are controlled for. Similar to the results for the US, this shows that the univariate impact of education on mortality is due to the fact that higher educated persons have better jobs and a higher income. When we control for the latter variables, education has much less of an own impact on mortality, possibly because people of higher education have knowledge and behavior conducive to better health.

The disadvantage combined with getting transfer income is reduced by more than half if financial variables are controlled for and the higher mortality of the persons where the main source of income is unknown is also neutralized. In Model 5 we find a surprising change of the results for marital status: The disadvantage of all single persons compared to married persons has steeply increased after controlling for the financial variables. We can not offer a valid explanation for this effect but it is at least a possible and logical conclusion from the modeling procedure that in Denmark single women in all three groups (divorced, widowed, never married) have a relatively wealthy status, so that they only have a mortality about 25 percent higher than that of the married women in Model 
4. When we now control for income and wealth, this positive effect can not hide their real disadvantage any longer, the latter which appears to be much higher than for men. This more than twofold mortality is partly due to a worse health status because in Model 6 , which controls for health, we see this disadvantage declining. The advantage of being wealthier disappears if income is controlled for, which means that it is income rather than wealth that is important for health and mortality. If wealth does not translate into income it may even have a slightly negative impact, since the rate ratios are well above 1 for the wealthier groups. Finally, it is impressing how robust the hazard ratios for income are against the inclusion of control variables: the gradient stays basically the same in all three models.

Model 6 includes days spent in hospital as control for health. It further slightly reduces some hazard ratios but has the most significant effect on the hazard ratio of those who still work compared to pensioners. In Models 4 and 4 active persons have a lower mortality but in Model 6 it turns out that this can be entirely explained by a better health status.

\subsection{Interaction models}

To address our central question whether socioeconomic mortality differences are stable or declining with increasing age, it is necessary to run interactions between age, i.e. the basic time variable of the model, and a variable for SES. In the following analysis, we will use income as an indicator for SES. This is because it has the highest separate impact on mortality (shown in Tables 1 and 2). The analysis with the other indicators for SES (not shown) sometimes show the same and sometimes less consistent results than with income but they never reveal very different or opposite patterns.

Figure 2 shows the mortality for men with interaction between age and income. Note that the graph does not show the increase in mortality with age but only the relative differences between the three income groups. 
Figure 2: Male mortality with interaction between age and income

$($ USA, based on Model 2, low income $=1)$

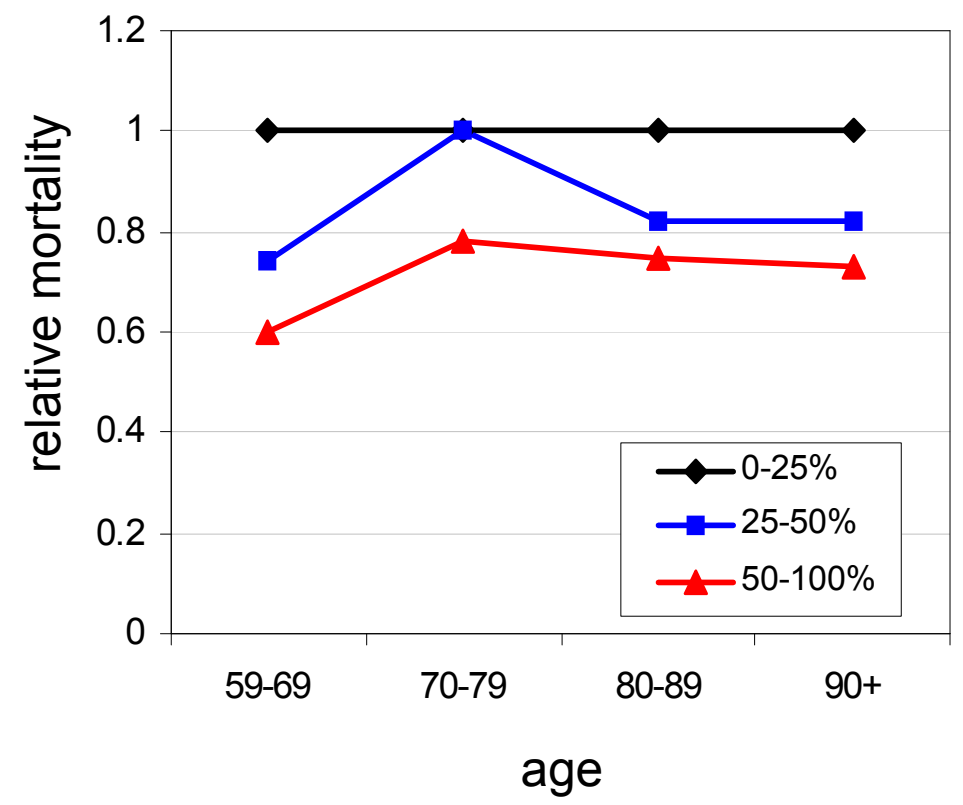

As we saw in Table 1, men with the highest income have a significantly lower mortality. The upper bound of the confidence interval for the richest group (red line) for the four age groups is $0.84,0.99,0.95$ and 1.16 . The confidence interval for the oldest group is wider because of low case numbers in this group. Those with a middle income also display a lower mortality, but this is not significant at the 5 per cent level. Far from significant in this graph are the fluctuations of differences over age groups. This suggests that mortality differences between income groups are relatively stable over age and obviously not declining with increasing age. The level of significance is not satisfactory, but the differences in the oldest age group are non-significant because of the wide confidence interval due to low case numbers rather than because of a mortality convergence in old age.

Figure 3 repeats Figure 2 (thin lines) and shows the same interaction based on Model 3 , which controls for the health variables (thick lines). 
Figure 3: Male mortality with interaction between age and income (USA, based on Model 3, health controlled (HC), low income = 1)

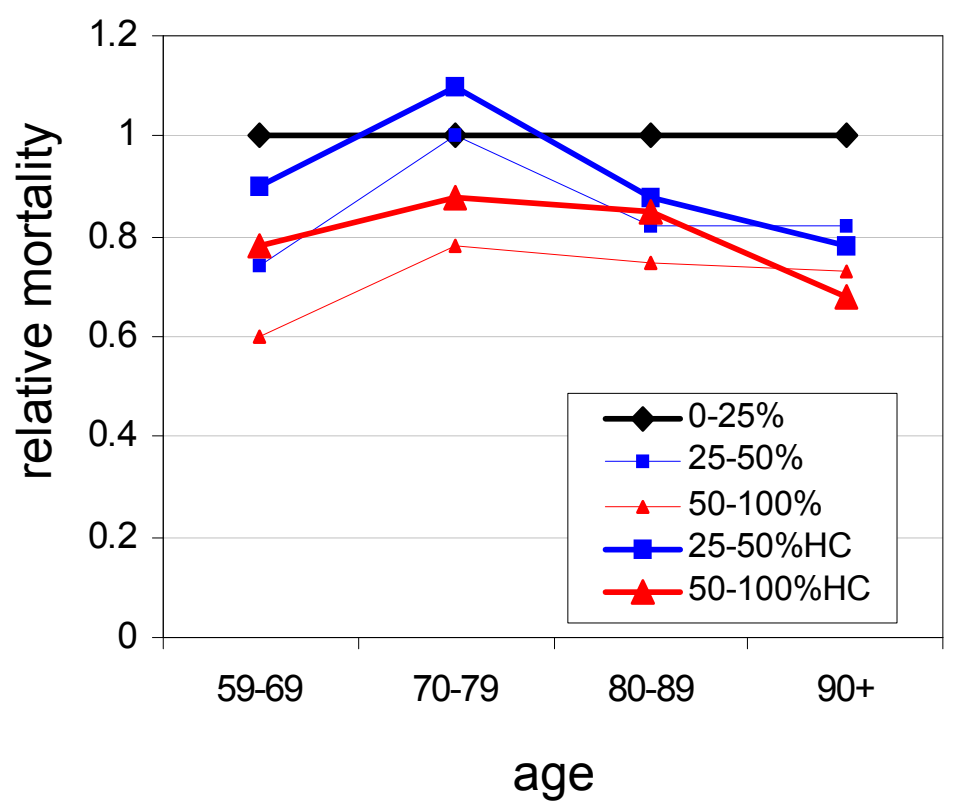

We see that when we control for health, the lines for middle and higher incomes get closer to the reference line. This effect is limited to younger age groups, with the consequence that mortality differences between poor and middle/high income groups tend to increase with age. But due to the small sample this increase is still far from significant.

The results for the USA reveal a certain pattern over age and an impact of health as a control variable on his pattern. But as mentioned already, the significance is not satisfactory and will be better for the following results for Denmark. 
Figure 4: Male mortality with interaction between age and income

(Denmark, based on Model 5, low income $=1$ )

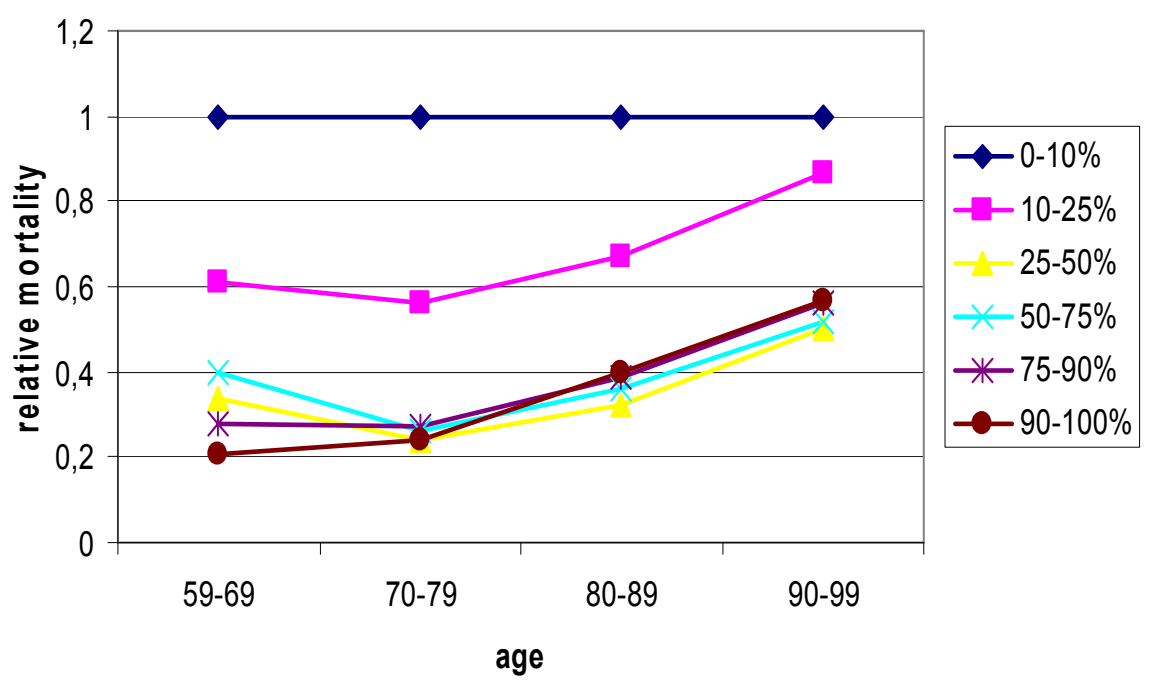

Figure 5: Male mortality with interaction between age and income

(Denmark, based on Model 6, health controlled (HC), low income = 1)

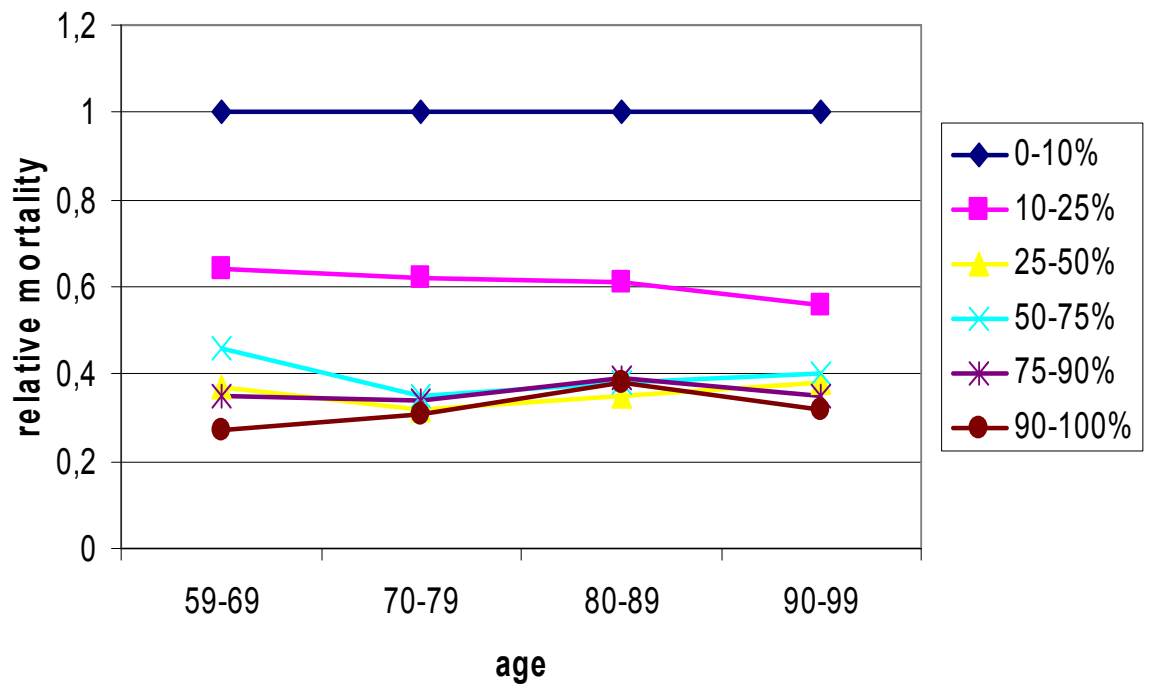

In contrast to the US, Figure 4 for Denmark shows a convergence of mortality differences over age. We observe in both countries the same change when we control for health: the mortality differences increase over age (USA, Figure 3) or remain stable over age (Denmark, Figure 5). The impact of health decline on social mortality differences can be illustrated further by an interaction between health and income. In all models age is controlled for. 
Figure 6: Male mortality with interaction between income and health (USA, based on Model 3, low income $=1)$

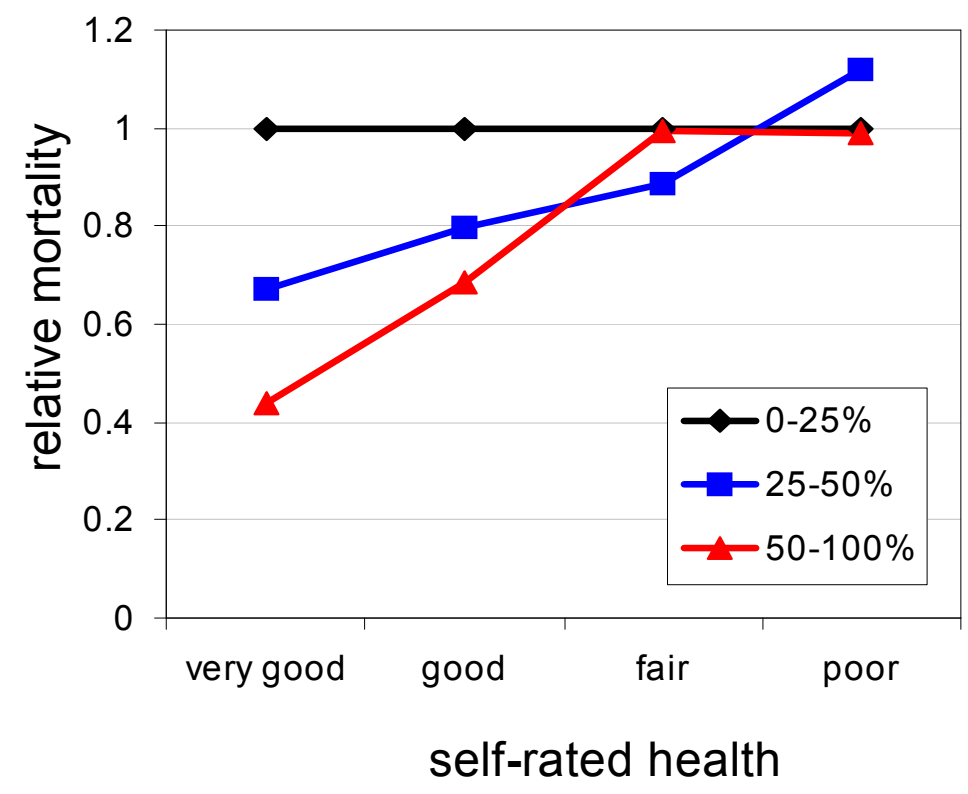

Figure 7: Male mortality with interaction between income and health (Denmark, based on Model 6, low income = 1)

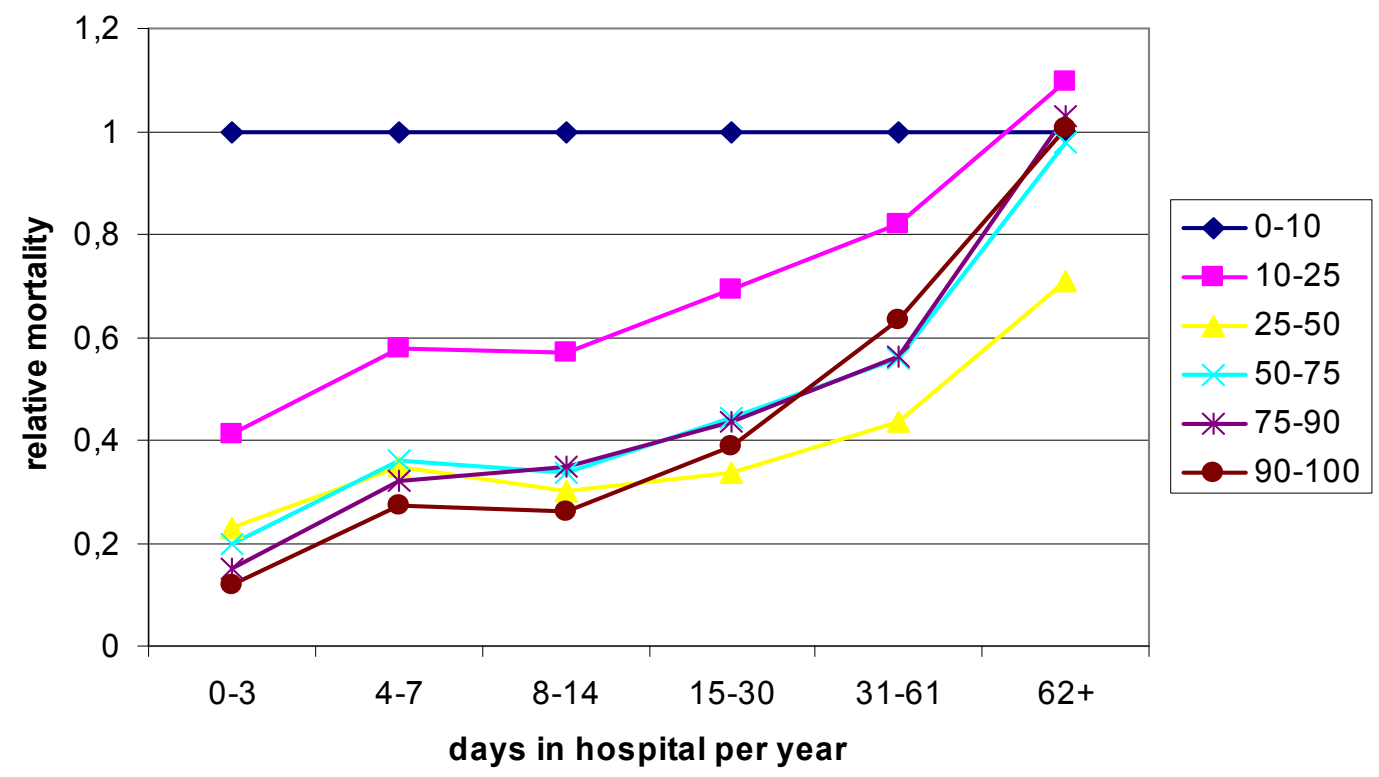


In the Models 3 and 6 we showed that, controlled for health, the impact of SES on mortality is smaller. With the interactions in Figures 6 and 7 we can reveal more about this relationship. These interactions show that income matters a lot when the person is in good health and that it has no impact when the person is in poor health. This means that poor health levels socioeconomic mortality differences. In Figure 6 the mortality difference between the lowest and the other income groups is only significant (at the 5 per cent level) when people are in good health (RR: 0.45, CI: 0.32-0.62; RR: 0.69, CI: 0.47-0.95).

If the health status is so important for the impact of SES on mortality, then the resulting question is whether the health decline with age is equally distributed between social groups, enough to result in a leveling of the mortality between social groups. Here, we want to use only the HRS data as it has better health information to report three aspects of health distribution. First, health declines generally with age: The correlation between age and average health during the study is $0.20 * * *$ for self-rated health and $0.34 * * *$ for objective health. The comparison of these numbers shows that there is an adjustment of the subjective perception of health that tends to "underestimate" health problems at high ages when a comparison to people of the same age shows that health problems are more common. But despite the general health decrease with increasing age, health is unequally distributed between income groups: Table 2 shows the other two aspects of health distribution: first, the average self-rated health status at the beginning of the observation and, second, the experience of health deterioration, both by the three income groups from above. A transition from good to bad health here means that at the beginning of the observation period a person was in either the best or the second best category of either self-rated or objective health and has moved down at least two levels by the end of observation. 
Table 3: Distribution and deterioration of health in different income groups by age

\begin{tabular}{l|ccccc} 
& age in 1992 & $\mathrm{n}=$ & $\begin{array}{c}\text { low } \\
\text { income }\end{array}$ & $\begin{array}{c}\text { middle } \\
\text { income }\end{array}$ & $\begin{array}{c}\text { high } \\
\text { income }\end{array}$ \\
\hline $\begin{array}{l}\text { Percentage enjoying very } \\
\text { good health at the }\end{array}$ & $59-68$ & 3140 & $\mathbf{5 8 . 2}$ & 78.4 & $\mathbf{8 8 . 7}$ \\
beginning of observation & $69-78$ & 4114 & 54.9 & 74.9 & $\mathbf{8 0 . 6}$ \\
& $79-102$ & 2122 & $\mathbf{5 2 . 6}$ & $\mathbf{6 9 . 8}$ & $\mathbf{7 3 . 3}$ \\
\hline \multirow{3}{*}{$\begin{array}{l}\text { Percentage experiencing } \\
\text { health deterioration }\end{array}$} & $59-68$ & 2408 & 13.1 & 9.6 & 6.5 \\
& $69-78$ & 2799 & 18.1 & 13.7 & 11.8 \\
& $79-102$ & 1273 & $\mathbf{2 2 . 6}$ & $\mathbf{2 3 . 9}$ & 19.1
\end{tabular}

Pearson's chi-square test has been applied to the original two-way tables (not shown) and the differences in the table are significant at the 0.01 per cent level except for the last row (see text).

It is difficult to measure how large health differences are and even more so to measure how these differences change with age. But it is obvious that even if health generally declines with age, people with lower income initially have a lower health status and are more likely to experience a health decline. The number of cases for the analysis of health decline is smaller than for the analysis of health at onset. This is because only healthy persons can be considered for a possible health decline. In the oldest age group (last row of the table), healthy persons are especially rare and selected, which may explain why the differences are not significant.

Concerning the question whether socioeconomic mortality differences decline with age or not, it is, finally, important to see if the impact of health status on mortality is stable across age groups. The Figures 8 and 9 show the interaction between age and health. 
Figure 8: Male mortality with interaction between age and self-rated health (USA, based on Model 3, very good health = 1)

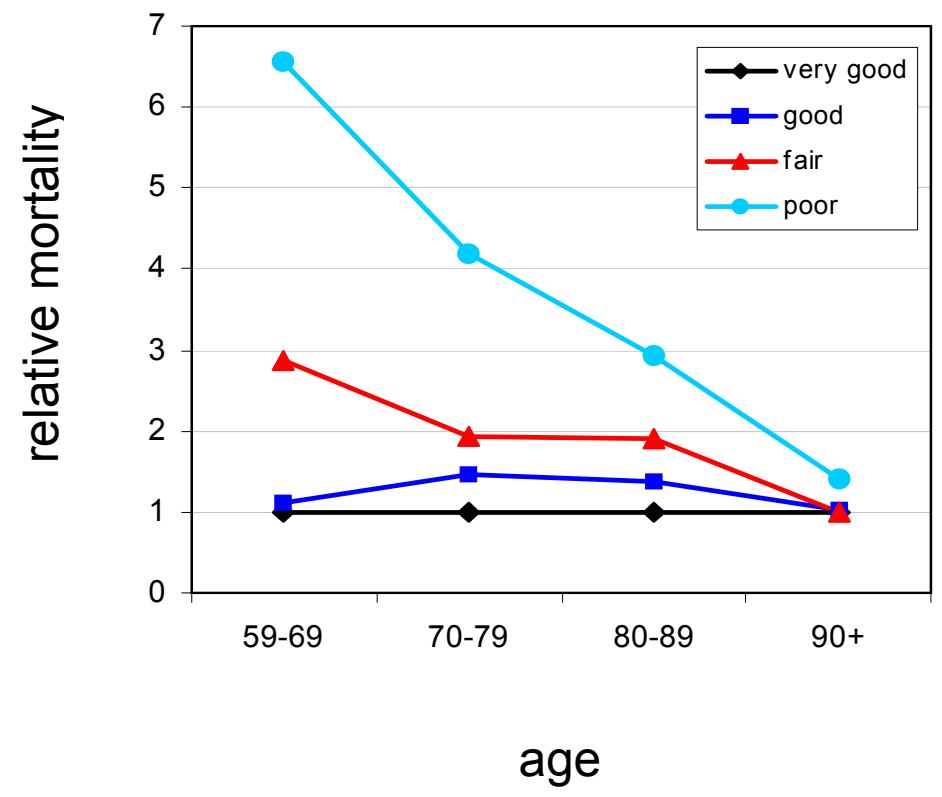

Figure 9: Male mortality with interaction between age and days in hospital (Denmark, based on Model 6, best health group = 1)

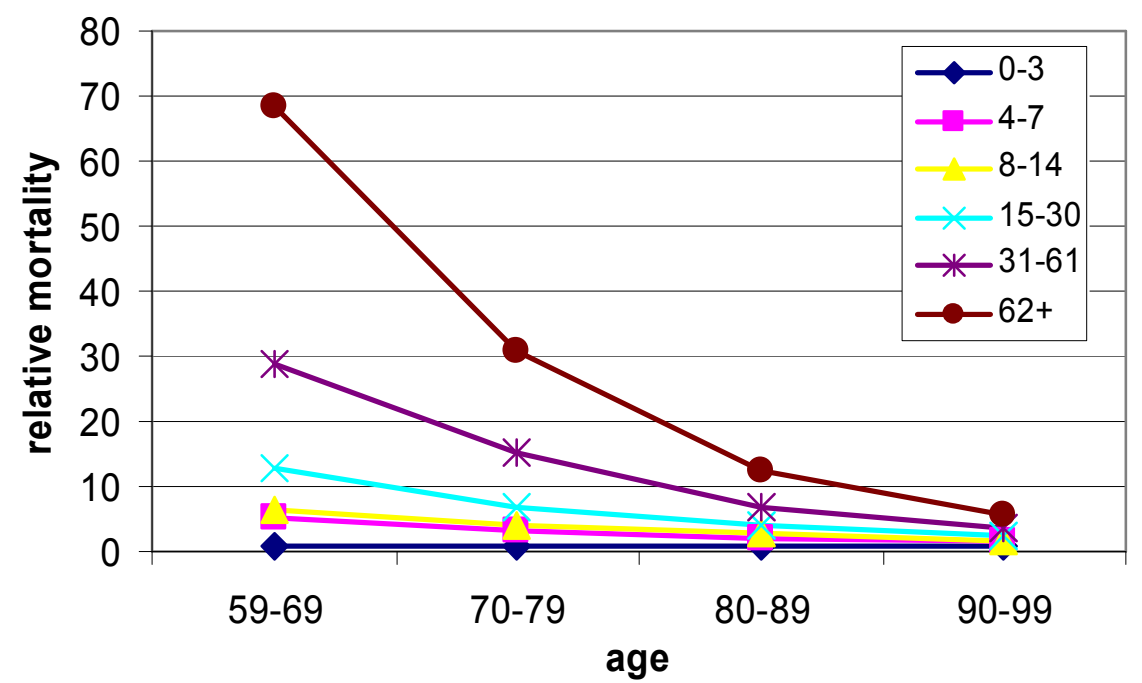


The interaction between age and self-rated health reveals that mortality differences between health groups are very large in younger age groups (age 59 to 69). In Figure 8, where all socioeconomic variables and the other health variables are controlled for, men with a poor self-rated health status at this stage have more than a six-fold higher mortality than those with very good health $(\mathrm{RR}=6.6, \mathrm{CI}=4.4-9.8)$. In Denmark (Figure 9), men who spend 62 days and more in hospital have a 70-fold higher mortality. These mortality differences converge very strongly in older age groups. The convergence in Figure 8 is not due to self-estimation by the respondents because the same interaction based on the objective health measure shows an even stronger convergence (results not shown). Note that, naturally, it is possible to represent the interaction in Figures 8 and 9 in absolute terms. Mortality, then, would increase strongly with age and the distance between the lines, i.e. the absolute differences in the mortality risk, would only slightly decrease with age. But since we do not focus on the general increase in mortality with age, the chosen representation in Figures 8 and 9 is more appropriate.

So far, the main result with respect to the convergence of socioeconomic mortality differences is that these differences are stable across age. However, they converge with deteriorating health. But health, in turn, assumes less importance for mortality in old age.

\subsection{Analysis of heterogeneity}

The next step is to address the problem of heterogeneity. Unfortunately, the model represented by equation (1), which includes the heterogeneity term $U$, did not show the expected results. For the US data, neither aML nor STATA 8 was able to identify heterogeneity in the estimation procedure. This is most likely due to the sample size, an insufficient observation time, or insufficient variation in time varying variables, and not due to the absence of heterogeneity in the sample because even in models with very few variables heterogeneity was not found.

The normal STATA frailty model applied to the Danish data that controls for unobserved heterogeneity in the traditional manner converged but only shows a minimal impact of mortality selection on the mortality pattern across age, as expected: after 
controlling for unobserved heterogeneity, socioeconomic mortality differences converge less with age. But this change is very small and thus not reported here with the help of graphs.

In the method section we described our reasons for believing that the way STATA controls for unobserved heterogeneity and, correspondingly, Figures 2 to 5 underestimate socioeconomic mortality differences at high ages which results in a converging pattern over age that may be entirely due to selection processes and not due to a decreasing impact of SES on mortality on the individual level. The results of the new method are described in the following.

To apply our method it was necessary to do a number of simplifications compared to the multivariate time-varying measurement of the six different income groups we used in the previous models. We computed the average income over time for each person and divided the population into a poor group, the poorest income quartile, and a rich group, that is, the rest. The alternative (two groups of 50 percent each) would not have been a better option because only the poorest 25 percent show higher mortality really. These changes in the measurement of SES resulted in a slightly different pattern over age, but we see in Figure 10 that with the new simpler measurement mortality differences between income groups still converge in higher ages.

Table 3 contains the necessary information to apply each step of our procedure. From the left to the right side of the table we have the survival from the beginning to the end of each age range, the hazard rate (deaths divided by exposures), we have the assumed degree of heterogeneity $\sigma^{2}$ and the resulting average frailty $\bar{z}$. The average frailty decreases with increasing age because the individuals with higher frailty die earlier. This decrease is steeper in the poor group because mortality is higher. The next column contains the corrected hazard, which is the hazard divided by the frailty according to equation (2), and for the older age groups it is the hazard divided by the product of the frailties of all younger age groups according to equation (4). The column with uncorrected rate ratios (RR) just contains the hazard of the rich divided by the hazard of the poor for each age group. These numbers can be seen in the graph. Here, the rich group becomes the reference category equal to one at all ages. The column with corrected RR is the same but based on the corrected hazards. 
Table 4: Calculation of rate ratios based on an assumed degree of heterogeneity

\begin{tabular}{l|cccccccc} 
& Age & Survival & Haz. Rate & $\sigma^{2}$ & $\bar{z}$ & corr. Haz. & uncorr. RR & corr. RR \\
\hline Rich: & $59-69$ & 0.879 & 0.00098 & 0.1 & 0.987 & 0.00099 & 0.655 & 0.651 \\
& $70-79$ & 0.649 & 0.00246 & 0.1 & 0.958 & 0.00261 & 0.646 & 0.627 \\
& $80-89$ & 0.256 & 0.00689 & 0.1 & 0.873 & 0.00835 & 0.708 & 0.646 \\
& $90-99$ & 0.016 & 0.01792 & 0.1 & 0.661 & 0.03284 & 0.777 & 0.632 \\
& & & & & & & & 1 \\
7
\end{tabular}

Figure 10 shows the uncorrected RR, the correction that is based on the assumption $\sigma^{2}=0.1$ (on which the calculations in Table 3 are based), and another correction based on the assumption $\sigma^{2}=0.2$.

Figure 10: male mortality with interaction between age and income and control for different degrees of heterogeneity $($ Denmark, poor $=1)$

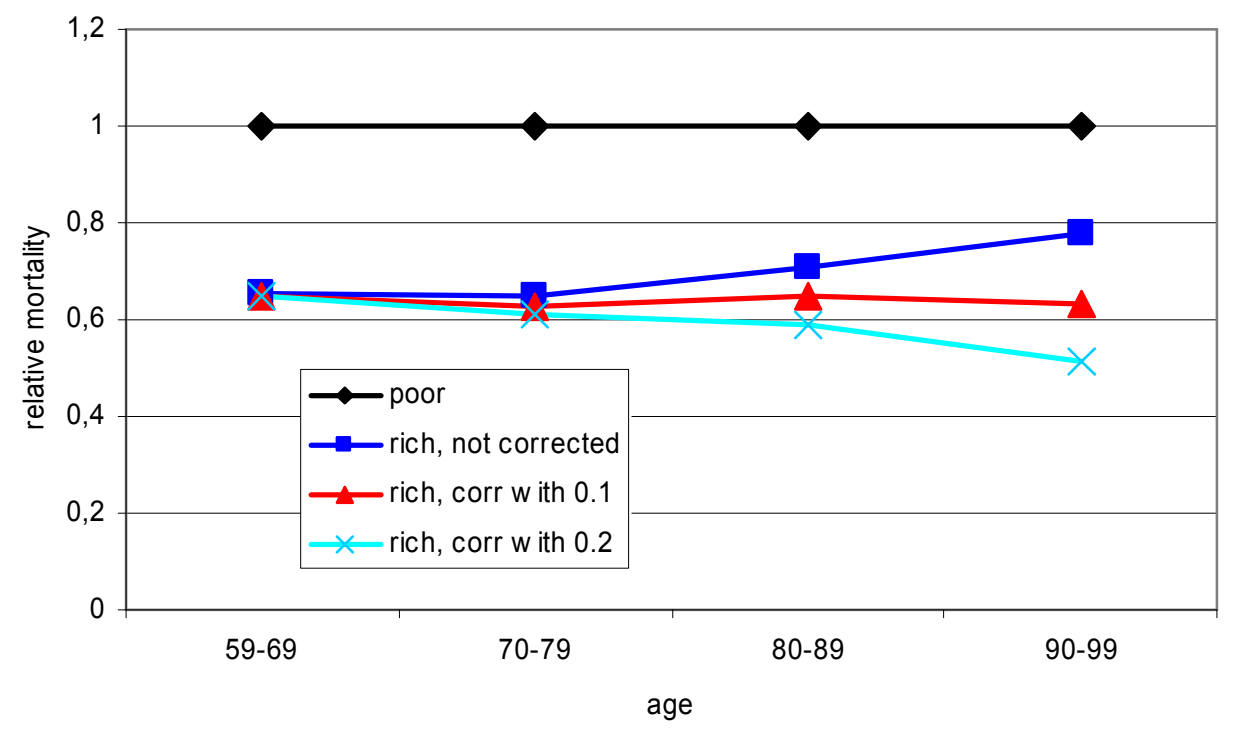

We see that even moderate and realistic assumptions about the degree of heterogeneity in a population can have an important impact on the age trajectory of social mortality differences. 


\section{Discussion}

The most important results from the main effect models in Table 1 and Table 2 are that income has a higher impact on mortality than education and that marital status works differently for men and women. In the following these results will be discussed briefly before we address the main question whether socioeconomic mortality differences decline with age. Concerning these differences the main result is that they do not decline with age but with declining health. Among other factors that we analyzed, unobserved heterogeneity seems to have an impact on these changes over age.

The surprisingly higher mortality for men with an intermediate education that we found in the HRS data has been observed also elsewhere (e.g. Liang et al. 2002). It has been interpreted as an educational mortality crossover due to selective mortality. An alternative explanation is that, holding income constant in the model, higher education means that the aforementioned education is not translated into higher income. This could be because the person never got a job that matches his educational level or he lost the job and experienced downward mobility that may have been health related. This interpretation is supported by the fact that the excess mortality for men of intermediate education concentrates on the lower income and poorer health groups (results not shown). It also suggests that education is not beneficial on its own but only combined with higher income (Hoffmann 2005). A possible conclusion is that education as a measurement of SES has, besides some advantages, the disadvantage of being too stable across the life course. In this regard, it is an advantage of this study that the social status has been measured in many dimensions. This is especially important for old age where, except for the fact that the occupational status is less important, it is not exactly known which dimensions define SES.

In most parts of this study we concentrated on income as indicator for SES; this because a choice for one dimension is necessary for the application and presentation of some analytical steps and also because this variable has a much greater influence on mortality than all other variables. In fact, for both countries educational mortality differences decreased much after financial variables were included in the model whereas mortality differences between income and wealth groups are relatively stable (Table 1 and Table 2). 
Our conclusion that higher income, as a consequence of higher education, has a much stronger direct impact on mortality than education, is different from results by Smith (2003 and 2004). He finds that financial variables only have a small impact on the onset of diseases, whereas education is important for new health events. We see three possible explanations for these inconsistent findings: first, the differences between pre-retirement and retirement ages (Smith 2003:22). Second, since our multivariate analysis concentrated on the event of death it can not be excluded that there are differences between the predictors of health and the predictors of mortality. Third, there may be differences between the predictors of the onset of diseases and the predictors of the overall health status. There are reasons to believe that controlling for baseline health status hides the influence of SES on mortality (Hoover 2003:123; Martelin 1996:127). The surprising result that single US women have fewer disadvantages than men and single Danish women have more disadvantages than men needs further investigation and can not be addressed in this study. The finding that divorced or never married women have lower mortality than married women if and only if we control for income and wealth (Model 2) may be due to an under-representation of institutionalized divorced or never married unhealthy women in the sample but it is more likely to show a real disadvantage of married women. The scope of our study does not allow for a detailed analysis of the reasons. But the fact that the sex difference emerges only after controlling for income and wealth may indicate that married women profit from higher material resources. Besides, they do not have an advantage or may even have a disadvantage when being married net of the other factors in our analysis. Grundy and Slogett (2003) argued that women experience fewer disadvantages of being single than men because they engage in unhealthy behavior in such situations to a smaller extent (Johnson et al. 2000) and are more likely to complement their singlehood with social networks (Goldman et al. 1995). In addition, they may even suffer in a marriage where they are likely to be the younger and healthier partner whose role it is to care for the ill spouse (Beckett et al. 2002).

The results for our main question of converging socioeconomic mortality differences will be discussed now in the order they confirm or contradict arguments 1 to 7 in the introduction. Even before controlling for heterogeneity, which will be discussed later, we find that socioeconomic mortality differences are stable across age groups and that 
instead of increasing age, poor health is the equalizer for social mortality differences. We are able to make a distinction between increasing age and health deterioration by controlling for health in Figures 3 and 5 and by the interaction between health and income in Figures 6 and 7. Our interpretation is a universal shift from social to biological determinants of mortality takes place when health decreases (argument 1). This does not mean, however, that social inequalities no longer exist after health has become poor. It rather raises the questions as to what extent health differences are caused by SES and whether social inequality at old age is incorporated in a more or less severe health decline and that therefore there is no longer social inequality in the transition from poor health to death. Thus, the question of social inequality in health is analogous to and becomes part of the question of social inequality in mortality.

Research findings reveal clear socioeconomic health differences at old age (Breeze 2000; Huisman et al. 2003). The question of convergence or divergence with age is as unclear for health differences as it is for mortality differences. Ross and Wu (1996) find that health differences increase up to age 90 . In our study we can only make an attempt to analyze health differences which reveals increasing health differences because from already unequally distributed health at onset, the rate for health deterioration is also higher for low income groups (Table 3).

Our finding that money matters less in poor health also helps to reject the assumption that money is of major importance to people in bad health to get good treatment to prevent them from dying. It is more convincing to think of social mortality differences as a process that already starts with social differences in health. Concerning the converging impact of declining health on mortality differences: the theoretically simple scenario that a socially mixed sample will experience a simultaneous health decline that would level social differences in mortality will practically never happen. The health decline of upper class persons will either be delayed, start on a higher health level or will be slower. Therefore, it is difficult to say if the potentially leveling impact of health decline is actually effective. This is because poor health is likely to be to a large extent the result of low SES and thus it is unequally distributed.

To conclude on this point we propose that even if it is plausible to assume that increasing age is generally combined with worsening health it is worth to keep these two 
dimensions of aging separate for analytical purposes. This is because age increases for everyone but health decline is very different for different social groups.

The convergence of socioeconomic mortality differences with worsening health but not with age questions the majority of studies that do not separate age and health decline and find socioeconomic mortality differentials that converge with age. The recent study by Huisman et al. (2004) is interesting in this regard. The authors have studied socioeconomic inequalities in mortality, having used very good data from 11 European countries. They have found that mortality differentials decrease with age in most countries but that they are stable and also increase in others. We also find a difference between the USA and Denmark in the age patterns of social mortality differences (Figures 2 and 4). Although the results for the USA are not statistically significant and we can not exclude that differences in the measurement between the two countries have an impact, it is possible that the social situation for elderly people and the welfare state in these two countries is responsible for these differences: Denmark has almost universal pension and health insurance coverage whereas in the USA social security for the elderly is much less comprehensive, leading to the fact that social inequality among the elderly is higher than at younger ages. This means that the second factor mentioned in the introduction probably has an influence.

The third argument and other similar explanations that are based solely on the temporal distance to working age or on the numerical age can be ruled out according to our findings as we show that increasing age as such, without a health decline, does not lead to converging mortality differences.

The influence of mortality selection and unobserved heterogeneity (argument 4) also partly explains the observed convergence of socioeconomic mortality differences at old age. Its impact differs between the standard method of controlling for heterogeneity and our new method which, for samples with left truncation, reveals a higher impact of mortality selection and seems to be superior to the normal inclusion of a term for heterogeneity in a statistical package like STATA or aML.

We can not specifically test the existence of factors 5,6 , and 7 here. They all suggest that there are increasing social mortality differences over age. To the extent that we can rule out some of the arguments pointing in the opposite direction, we generally suggest that there is no convergence of mortality differences and that the impact of SES on 
mortality on the individual level is stable or increasing. This applies even more so because argument 4 (unobserved heterogeneity) seems to explain the convergence.

As to our method, we do single calculations in single steps to impose the degree of heterogeneity that we assume and to keep track of the consequences and changes. This implies that there is a drawback, namely that we have to analyze the impact of income on mortality in a much simpler way than a model would do, namely time-constant, dichotomous and univariate. There is a trade of between observing as much heterogeneity as possible by including many variables in sophisticated models on the one hand, and keeping the procedure simple to be able to observe the decisive changes in unobserved heterogeneity and frailty on the other hand. The first strategy has many advantages and we interpret the results. But should our findings from the second strategy be valid, we can not say much about changes in socioeconomic mortality differences over age without taking into account this very strategy, i.e. without taking into account the impact of the systematically different change of frailty over age in different social groups. We show that normal modeling is likely to underestimate socioeconomic differences at old age and that it reveals a convergence that is an artifact of the compositional change over age (Figure 10). So far we can not quantify exactly this underestimation, mainly because the measurement of heterogeneity causes some statistical, computational, and data related problems, but we hope to contribute to the development of better methods that work in this direction. 


\section{Reference List}

Adams Peter, Hurd Michael D, Mcfadden Daniel, Marrill Angela, Ribeiro Tiago. (2002). "Healthy, wealthy, and wise? Tests for direct causal paths between health and socioeconomic status." Journal of Econometrics, 112, 1: 3-56.

Auerbach James A, Krimgold Barbara K. (2001). Income, Socioeconomic Status and Health: Exploring the Relationship. NPA Report, Washington, DC: National Policy Association et al.

Barbi Elisabetta. (2003). Annals of EpidemiologyAssessing the rate of ageing of the human population." MPIDR Working Paper WP 2003-008, Max Planck Institute for Demographic Research, Rostock.

Beckett Megan. (2000). "Converging health inequalities in later life - an artifact of mortality?" Journal of Health and Social Behaviour, 41: 106-119.

Beckett Megan, Goldman Noreen, Weinstein Maxine, Lin I-Fen, Chuang Yi-Li. (2002). "Social environment, life challenge, and health among the elderly in Taiwan." Social Science and Medicine, 55: 191-209.

Breeze Elizabeth. (2000). Health inequalities persist into old age: results from the longitudinal study. In: Butler RN, Jasmin C. Longevity and Quality of Life: Opportunities and Challenges. New York et al.: Kluwer Academic Press / Plenum Publishers: 171-179.

Caselli Graziella, Vaupel James W, Yashin Anatoli. (2000). "Longevity, heterogeneity and selection." Paper presented at the XL Riunione Scientifica della Società Italiana di Statistica, Florence, April 26-28.

Crystal Stephen, Shea Dennis. (1990). "Cumulative advantage, cumulative disadvantage, and inequality among elderly people. " The Gerontologist, 30, 4: 437-443.

Dannefer Dale. (2003). "Cumulative advantage/disadvantage and the life course: crossfertilizing age and social science theory." Journal of Gerontology: Social Sciences, 58B, 6: 327-337.

Davey Smith George, Gunnell David, Ben-Shlomo Yoav. (2001). Life-course approaches to socio-sconomic differentials in cause-specific mortality. In: Leon DA, Walt G. Poverty, Inequality and Health: an International Perspective. Oxford: Oxford University Press: 88-124.

Doblhammer Gabriele. (2000) "Reproductive history and mortality later in life: a comparative study of England \& Wales and Austria." Population Studies, 54, 2: 169-176.

Ferraro Kenneth F, Farmer Melissa M. (1996). "Double jeopardy, aging as leveler, or persistent health inequality? A longitudinal analysis of white and black 
Americans." Journal of Gerontologie: Social Sciences, 51b: 319-328.

Fox Anthony J, Goldblatt P O, Jones D R. (1985). "Social Class Mortality Differentials: Artefact, Selection or Life Circumstances?" Journal of Epidemiology \& Community Health, 39:1-8.

Goldman Noreen. (2001). "Social inequalities in health: Disentangling the underlying mechanisms." Annals of the New York Academy of Sciences, 954, December: 118139.

Goldman Noreen, Korenman Sanders, Weinstein Rachel. (1995). "Marital status and health among the elderly." Social Science and Medicine, 40: 1717-1730.

Grundy Emily, Sloggett Andy. (2003). "Health inequalities in the older population: the role of personal capital, social resources and socio-economic circumstances." Social Science and Medicine, 56: 935-947.

Hoffmann Rasmus. (2005) "Do socioeconomic mortality differences decrease with rising age?" Demographic Research, (forthcoming).

Horiuchi Shiro, Wilmoth John. (1998). "Deceleration in the age pattern of mortality at older ages." Demography, 35, 4: 391-412.

House James S, Kessler Ronald C, Herzog A Regula. (1994). "The social stratification of aging and health." Journal of Health and Social Behaviour, 35: 213-234.

Hoover Kevin D. (2003). "Some causal lessons from macroeconomics." Journal of Econometrics, 112(1): 121-25.

Huisman Martin, Kunst Anton E, Andersen Otto, Bopp M, Borgan J-K, Borrell C, Costa G, Deboosere P, Desplanques G, Donkin A, Gadeyne S, Minder C, Regidor E, Spadea T, Valkonen T, Mackenbach J-P. (2004). "Socioeconomic Inequalities in Mortality Among Elderly People in 11 European Populations." Journal of Epidemiology \& Community Health, 58(6): 468-75.

Huisman Martijn, Kunst Anton E, Mackenbach Johan P. (2003). "Socioeconomic inequalities in morbidity among the elderly; a European overview." Social Science and Medicine, 57: 861-873.

Johnson Norman J., Backlund Eric, Sorlie Paul D., Loveless, Catherine A. (2000). "Marital status and mortality: The National Longitudinal Mortality Study." Annals of Epidemiology, 10: 224-238.

Kunst Anton. (1997). Cross-national comparisons of socioeconomic differences in mortality. Rotterdam, Erasmus University: ThelaThesis.

Liang Jersey, Bennet Joan, Krause Neal, Kobayashi Erika, Kim Hyekyung, Brown J. Winchester, Akiyama Hiroko, Sugisawa Hidehiro, Jain Arvind. (2002). "Old age mortality in Japan: Does the socioeconomic gradient interact with gender and age?" Journal of Gerontology: Social Sciences, 57b: 294-307. 
Lillard Lee A., Panis Constantijn W A. (2003). aML Multilevel Multiprocess Statistical Software Version 2.04., Los Angeles, California: Econware (http://www.appliedml.com).

Mackenbach Johan P, Kunst Anton E, Valkonen Tapani. (1999). "Socioeconomic inequalities in mortality among women and among men: An international study." American Journal of Public Health, 89: 1800-1806.

Manton Kenneth G, Stallard Eric, Vaupel James W. (1986). "Alternative models for the heterogeneity of mortality risk among the aged." JASA, 81, 395: 635-644.

Marmot Michael G, Shipley Martin J. (1996). "Do socioeconomic differences in mortality persist after retirement? 25 year follow up of civil servants from the first Whitehall study." British Medical Journal, 313: 1177-1180.

Martelin Tuija. (1996). Socio-demographic differentials in mortality at older ages in Finland. In: Graziella Caselli and Alan D. Lopez Health and mortality among elderly populations. International Studies in Demography. Oxford: Clarendon Press. 112-134.

McCord Colin, Freeman Harold P. (1990). "Excess Mortality in Harlem." New England Journal of Medicine, 322: 173-177.

Nam Charles B. (1995). "Another look at mortality crossovers." Social Biology, 42: 133-143.

O'Rand Angela M. (1996). "The Precious and the Precocious: Understanding Cumulative Disadvantage and Cumulative Advantage Over the Life Course." The Gerontologist, 36: 230-238.

Otterblad Olausson Petra. (1991). "Mortality Among the Elderly in Sweden by Social Class." Social Science and Medicine, 32: 437-40.

Pappas Gregory, Queen Susan, Hadden Wilbur, Fisher Gail. (1993). "The Increasing Disparity in Mortality Between Socioeconomic Groups in the US, 1960 and 1986." New England Journal of Medicine, 329(2): 103-9.

Preston Samuel H, Elo Irma T. (1995). "Are educational differences in adult mortality increasing in the United States?" Journal of Aging and Health, 7: 476-496.

Ross Catherine E, Wu Chia-Ling. (1996). "Education, age, and the cumulative advantage in health." Journal of Health and Social Behaviour, 37: 104-120.

Schrijvers Carola T M, Stronks Karien, van de Mheen H Dike, Mackenbach Johan P. "Explaining educational differences in mortality: the role of behavioral and material factors." American Journal of Public Health, 89(4): 535-540.

Smith James P. (2004). "Unravelling the SES health connection." IFS Working Papers W04/02, Institute for Fiscal Studies. 
Smith James P. (2003). "Consequences and Predictors of New Health Events." NBER Working Papers 10063, National Bureau of Economic Research, Inc.

Smith James P. (1999). "Healthy Bodies and Thick Wallets: the Dual Relation between Health and Economic Status." Journal of Economic Perspectives, 13(2): 145-66.

Smith James P, Kington Raynard S. (1997). Race, socioeconomic status and health in late life. In: Martin LG, Soldo BJ. Racial and Ethnic Differences in the Health of Older Americans. Washington: National Research Council: 105-162.

Soldo Beth J, Hurd Michael D, Rodgers Willard L, Wallace Robert B. (1997). "Assets and health dynamics among the oldest old: an overview of the AHEAD study." The Journals of Gerontology, 52b, Special Issue: 1-20.

StataCorp (2003). Stata Statistical Software: Release 8.0. College Station, TX: Stata Corportation (http://www.stata.com).

Stronks Karien. (1997). Socio-Economic Inequalities in Health: Individual Choice or Social Circumstances? Dissertation. Rotterdam. Erasmus University.

Valkonen Tapani. (2001). "Life Expectancy and Adult Mortality in Industrialized Countries." International Encyclopedia of Social and Behavioral Sciences. 88228827.

Vaupel James W, Manton Kenneth G, Stallard Eric. (1979). "The impact of heterogeneity in individual frailty on the dynamics of mortality." Demography, 16, 3: 439-454.

Warren John R, Kuo Hsiang-Hui. (2003). "How to measure 'what people do for a living' in Research on the Socioeconomic Correlates of Health." Annals of Epidemiology, 13, 5: 325-334. 